\title{
Tercer Molar Ectópico Impactado en Zona Retromolar. Reporte de Caso
}

\author{
Ectopic and Impacted Third Molar in Retromolar Zone. A Case Report
}

Ramón Fuentes Fernández \& Gonzalo Oporto Venegas

FUENTES, F. R. \& OPORTO, V. G. Tercer molar ectópico impactado en zona retromolar. Reporte de caso. Int. J. Morphol., 27(1):35$38,2009$.

RESUMEN: El desarrollo dentario resulta de una complicada interacción entre el epitelio oral y el tejido mesenquimático subyacente. La interacción anormal de tejidos en este período podría resultar en el desarrollo y erupción de un diente ectópico. Terceros molares incluidos son una de las patologías más frecuentes encontradas en cirugías oral y maxilofacial. Su evaluación generalmente es radiográfica, y los de ubicación mesioangular son los más prevalentes en la mandibula. El presente reporte muestra un caso clínico de tercer molar incluido en la región retromolar mandibular. El diagnóstico se efectuó durante una evaluación por medio del análisis de una ortopantomografía en un paciente de sexo femenino de 51 años de edad. La pieza estaba ubicada en la zona retromolar mandibular derecha inmediatamente subcortical. Dado que se encontraba asintomática, sin signos radiográficos ni clínicos de patología, no fue indicada la exodoncia; sin embargo, es importante considerar esta variación anatómica y una posible resolución quirúrgica de ella ante la posible rehabilitación protésica del área.

PALABRAS CLAVE: Variación anatómica; Odontogénesis; Diente ectópico; Diente impactado; Tercer molar.

\section{INTRODUCCIÓN}

El desarrollo dentario resulta de una complicada interacción de múltiples pasos entre el epitelio oral y el tejido mesenquimático subyacente. Una serie de complejas reacciones tisulares resultan en la formación del diente maduro. La interacción anormal de tejidos durante el desarrollo podría resultar en el desarrollo y erupción de un diente ectópico ( Büyükkurt et al., 2005). Los terceros molares incluidos corresponden a una de las patologías más frecuentes encontradas en las cirugías oral y maxilofacial (Salmerón et al., 2008). Éstos se categorizan de acuerdo a su posición y profundidad en relación al segundo molar, su proximidad con la rama ascendente de la mandíbula y su angulación hacia el segundo molar adyacente. Su evaluación generalmente es radiográfica. Los terceros molares impactados mesioangularmente son los más prevalentes en el arco mandibular. Los molares ectópicos hacen referencia cuando se encuentran en posiciones inusuales o desplazados de su normal localización anatómica pudiéndose encontrar en la rama ascendente de la mandíbula, región subcondilar, proceso coronoides, seno maxilar o región infraorbitaria. No se han establecido límites precisos en la clasificación de piezas ectópicas (García et al., 2007).
Terceros molares impactados en la rama mandibular y en la región subcondilar son poco frecuentes (Tümer et al., 2002). Se asocian frecuentemente con quistes dentígenos, siendo ésta una razón descrita que podría asociar su desplazamiento de la región original, así como un movimiento eruptivo abortado o bloqueo de su erupción por una lesión como un tumor odontogénico (García et al.). La remoción de terceros molares incluidos ectópicos asociados a quistes está indicada, pero es bastante difícil, realizándose técnicas endoscópicas para su resolución (Suárez-Cunquiero et al., 2003). Se han descrito piezas incluidas ectópicas en el seno maxilar y en la fosa infratemporal (Salmerón et al.), así como casos de molares con raíces insertas en una osificación en el seno maxilar con sintomatología dolorosa (Kamei et al., 2001). Algozaín \& Viñas (2008), reportaron un caso de desplazamiento de un fragmento de tercer molar durante el acto quirúrgico al espacio parafaríngeo.

A continuación se reporta el caso de un tercer molar ectópico incluido en la zona retromolar, orientado hacia la zona ascendente de la rama mandibular. 


\section{REPORTE DE CASO}

El hallazgo del tercer molar ectópico impactado fue realizado por medio de una radiografía panorámica (Fig. 1) en una evaluación diagnóstica de ingreso a la Clínica Odontológica Docente Asistencial de la Universidad de La Frontera, en un paciente de sexo femenino de 51 años de edad, quien consultó por tratamiento Odontológico.
Durante la anamnesis remota, no hubo relato de antecedentes de trauma dentoalveolar ni de enfermedades graves durante la infancia y adolescencia. En la anamnesis próxima, la paciente señaló tener un estado de salud bueno, no se encontraba en tratamiento médico ni consumía medicamentos con frecuencia.

La pieza dentaria se encontraba en la mandíbula, en la zona retromolar derecha, perpendicular al ángulo de la mandíbula, subcortical e inmediatamente sobre el canal

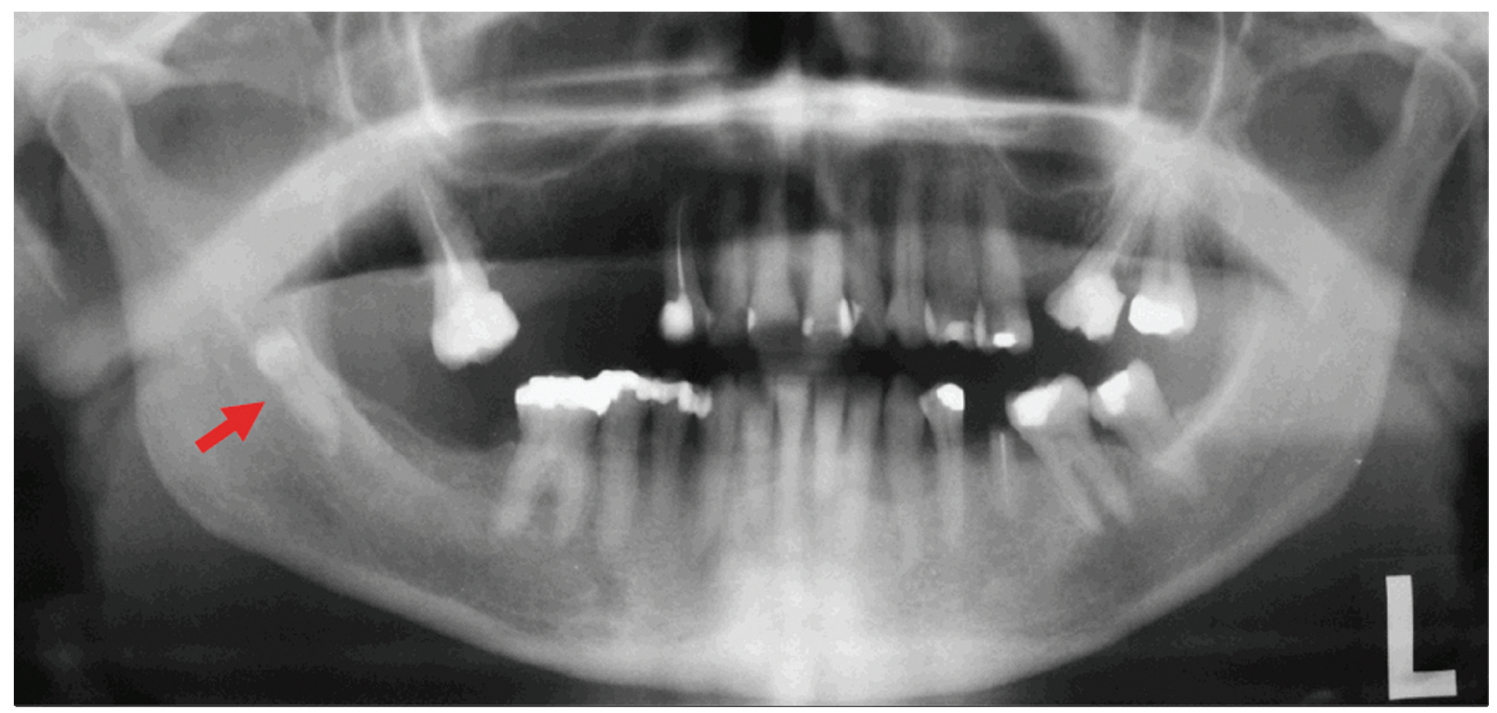

Fig. 1. Radiografía panorámica señalando la posición del tercer molar ectópico.

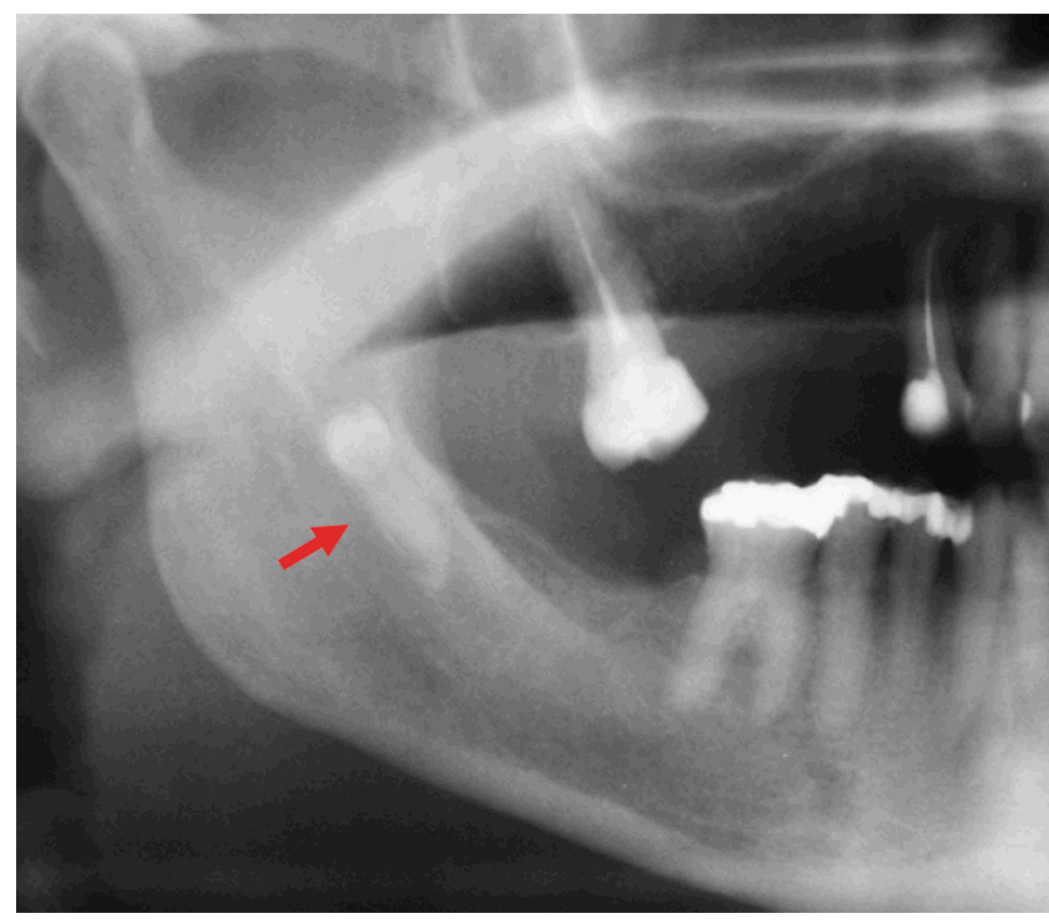

Fig. 2. Radiografía panorámica señalando la posición del tercer molar ectópico en hemiarcada derecha. mandibular (Fig. 2). La corona orientada hacia el proceso condilar de la mandíbula, en estrecha relación al canal mandibular. El ápice radicular se orientaba hacia el borde basilar derecho del mismo hueso.

Al examen extra oral la paciente no evidenció alteraciones de tejidos blandos o duros, del mismo modo, no existió relato de sintomatología dolorosa espontánea, ante estímulos o durante la función; tampoco existió parestesia en la región facial. Al análisis de movimientos mandibulares, éstos se encontraban dentro de rangos normales.

La exploración clínica intraoral no arrojó alteraciones de color o forma en ningún tipo, así como tampoco hubo relato de dolor espontáneo o al estímulo en la zona retromolar y sus proximidades. No existía pérdida de la sensibilidad en dientes, encía, labio y/o lengua del lado donde se encontraba la pieza ectópica, como tampoco en el lado contralateral. 


\section{DISCUSIÓN}

Las piezas dentarias ectópicas son la resultante de alteraciones del desarrollo dentario, específicamente, de los tejidos a partir de los cuales se originan las piezas dentales (Büyükkurt et al.). Las teorías que explican la posición ectópica de los terceros molares, incluyen erupción aberrante por trauma y formación ectópica de los gérmenes (Salmeron et al.). Los antecedentes recabados en el reporte de este caso, señalan que la causa más probable de la posición ectópica del tercer molar es la formación del germen en la zona retromolar.

Si bien es cierto, la pesquisa de terceros molares ectópicos no es un hecho infrecuente en el campo de la odontología y cirugía de las regiones oral y maxilofacial (Salmerón et al.), la zona y posición en que se encuentren son tan variables como la frecuencia con que se reportan terceros molares ectópicos en cada área (García et al.). La variable antes señalada cobra importancia a la hora de analizar la anatomía topográfica del área donde se ubica el tercer molar, ya que la extracción de estas piezas sin justi- ficación clínica se reporta entre un $18 \%$ y $50.7 \%$ de los casos, o bien se indica la cirugía con criterio preventivo en cuanto evitar el desarrollo de otras patologías, tales como desarrollo de quistes, tumores, fractura a nivel del ángulo mandibular, pericoronaritis y reabsorción radicular del segundo molar (Algozaín \& Viñas-García). A raíz del análisis del caso, cabe señalar la importancia de, antes de tomar la decisión de proceder quirúrgicamente, evaluar los reparos y relaciones anatómicas, que permitirán al clínico prever con mayor certeza los riesgos y pronóstico del tratamiento, otorgando una evaluación de los posibles beneficios o perjuicios que pudieran tener para el paciente la excéresis quirúrgica de una pieza ectópica impactada que se presenta semiológicamente inafectada, sin antecedentes clínicos para desarrollar alguna de las patologías o alteraciones discutidas anteriormente. Por todo esto, resulta de suma importancia para el clínico conocer tanto la anatomía normal como las variaciones anatómicas de la región maxilofacial, a la hora de evaluar y resolver el tratamiento de una pieza retenida ectópica.

FUENTES, F. R. \& OPORTO, V. G. Ectopic and impacted third molar in retromolar zone. A case report. Int. J. Morphol., 27(1):35-38, 2009.

SUMMARY: Tooth develop results of several interactions between oral epithelium end underlying mesenchymatic tissue during odontogenesis. Abnormal relation of tissues could result in develop and eruption of an ectopic tooth. Impacted third molars are a frequent pathology in oral and maxillofacial surgery, it evaluation is commonly radiographic, and the most frequent position in jaw bone is mesioangular. This report wants to show an impacted third molar in mandibular retromolar region. Diagnosis was done through a orthopantomographic study during a clinical evaluation of 51 years of age female patient. Teeth was found sub cortical of right retromolar zone. Considering patient did not related or shown clinical signs of pathology, and radiograph neither had disease compatible signs, was resolved do not proceed to extraction. However, is important to consider this anatomical variation and a possible surgical resolution if a prosthetic rehabilitation of this area.

KEYWORDS: Anatomical Variations; Odontogenesis; Ectopic Tooth; Impacted Tooth; Third Molar.

\section{REFERENCIAS BIBLIOGRÁFICAS}

Algozaín, Y. \& Viñas García, M. Desplazamiento accidental hacia el espacio parafaringeo de un fragmento de un tercer molar inferior retenido. Rev. Cub. Estomatol., 45: 1 ene.- mar, 2008

Büyükkurt, M. C.; Tozoglu, S.; Aras, M. H. \& Yolcu Ü. Ectopic Eruption of a Maxillary Third Molar Tooth in the Maxillary Sinus: A Case Report. J. Contemp. Dent. Pract., 6(3):104-10. 2005

García, M. C.; Collado L. J.; Serrano, G. H.; Morillo, S, A. J.; Mateo, A. J.; Moreno, V. J.; Ruiz, L. L.; Nadal, C. B.
\& Quirós, A. P. Tercer molar ectópico a nivel de región infraorbitaria-seno maxilar. Rev. Esp. Cirug. Oral y Maxilofac., 29: 3, 2007.

Kamei, T.; Inui, M.; Nakamura, S. \& Tagawa, T. Bony Ossicle in the Maxillary Sinus Containing a Tooth. J. oral Maxillofac. Surg., 59:1108-11, 2001.

Salmerón, J.I.; Plasencia, J.; Pujol, C. \& Vila, N. Ectopic third molar in condylar region. Int. J. Oral Maxillofac. Surg., 37: 398-400, 2008. 
Suárez-Cunqueiro, M.; Schoen, R.; Schramm, A.; Gellrich, N. \& Schmelzeisen, R. Endoscopic approach to removal of an ectopic mandibular third molar. 41: 340-2, 2003.

Tümer, C.; Eset, A. \& Atabek, A. Ectopic impacted mandibular third molar in the subcondylar region associated with a dentigerous cyst: A case report. Quintessence Int., 33:231-3, 2002
Dirección para Correspondencia:

Prof. Dr. Med. Dent. Ramón Fuentes Fernández Departamento de Odontología Integral

Facultad de Medicina

Universidad de La Frontera

Manuel Montt 112

Temuco - CHILE

Email: rfuentes@ufro.cl

Recibido : 16-09-2008

Aceptado: 22-11-2008 